See discussions, stats, and author profiles for this publication at: https://www.researchgate.net/publication/230558398

\title{
A system for imaging variable chlorophyll fluorescence of aquatic phototrophs
}

Article in Ophelia · August 2004

DOI: 10.1080/00785326.2004.10410215

CITATIONS

28

2 authors, including:

Michael Kühl

University of Copenhagen

436 PUBLICATIONS 15,112 CITATIONS

SEE PROFILE
READS

97

Some of the authors of this publication are also working on these related projects:

Project Biophotonics of diatoms: Linking frustule structure to photobiology (PhD project) View project

Project The Chemical Microenvironment of Chronic Biofilm Infections View project 


\title{
A SYSTEM FOR IMAGING VARIABLE CHLOROPHYLL FLUORESCENCE OF AQUATIC PHOTOTROPHS
}

\author{
Björn Grunwald ${ }^{1}$ and Michael Kühl2,* \\ ${ }^{1}$ Max-Planck Institute for Marine Microbiology, \\ Celsiusstr. 1, D-28359 Bremen, Germany. \\ ${ }^{2}$ Marine Biological Laboratory, Institute of Biology, University of Copenhagen, Strandpromenaden 5, DK-3000 \\ Helsingør, Denmark. \\ *Corresponding author: mkuhl@bi.ku.dk / http://www.mbl.ku.dk/mkuhl
}

\begin{abstract}
We describe a modular imaging system for mapping the variable chlorophyll fluorescence of photosynthetic organisms and tissues in the aquatic environment. The system is based on an array of blue LED's $(470 \mathrm{~nm})$ for excitation of chlorophyll and a modulated CCD camera equipped with a long-pass filter for detection of chlorophyll fluorescence $>665 \mathrm{~nm}$. The exposure of the sample with blue actinic light, non-actinic measuring light, and a flash of saturating light is based on a software-controlled sequence of variable pulse-widths of the LED's. The LED and the camera modulation are controlled via a custom designed timer-unit connected to a PC. We present examples of application for mapping the distribution of photosynthetic activity in coral tissue, communities of endolithic algae within coral skeleton as well as in tissue of didemnid ascidians harboring symbiotic cyanobacteria. It is possible to study spatio-temporal patterns of variable fluorescence (and the derived quantum yield of photosystem II-related electron transport) in heterogeneous aquatic systems at sub-mm spatial resolution.
\end{abstract}

Keywords: Photosynthesis, fluorescence imaging, corals, Prochloron, endolithic algae.

\section{INTRODUCTION}

The dynamic fluorescence characteristics of chlorophyll in photosynthetic organisms vary over time scales ranging from ps to hours, and chlorophyll fluorescence can be used as a sensitive and non-invasive indicator in photosynthesis studies. Variable fluorescence is thus an exceptional tool in studies of primary reactions in the biophysics and biochemistry of photosynthesis as well as in ecophysiological studies of stress and photosynthetic performance as a function of environmental variables (Govind- jee 1995, Schreiber et al. 1995). During the past decade, the measuring techniques for using variable chlorophyll fluorescence in noninvasive studies of photosynthesis have been refined significantly and measurements can now be undertaken in both natural and defined systems at scales ranging from single chloroplasts and cells to intact leaves, macroalgae, and assemblages of microalgae. Even underwater-equipment for in situ investigations has been developed (Ralph et al. 1997, Gorbunov et al. 2000, Kühl et al. 2001). A brief introduction to variable chlorophyll fluorescence is given in the methods section of this paper.

For environmental applications, most instrument developments have focused on measuring systems where the fluorescence characteristics are integrated over a certain surface area or volume. However, in aquatic systems like photosynthetic biofilms (Glud et al. 1999, Kühl \& Fenchel 2000), sediments (Fenchel \& Glud 2000 ), and in various aquatic organisms with photosynthetic symbionts (Kühl et al. 1995, Ralph et al. 2002, Kühl \& Larkum 2001) photosynthesis can exhibit a pronounced heterogeneous distribution. To resolve such heterogeneity, chlorophyll fluorescence imaging systems have been developed. Hitherto most applications have focused on terrestrial plants (but see e.g. Oxborough et al. 2000, BermanFrank et al. 2001). The applied measuring principles range from relatively simple light modulation approaches (e.g. Siebke \& Weis 1995, Oxborough \& Baker 1997, Nedbal et al. 2000) to advanced lifetime imaging systems (Holub et al. 2000). Several systems are now also com- 
A

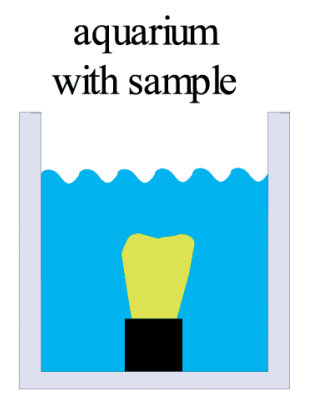

LED filter $\quad$ CCD camera
ring

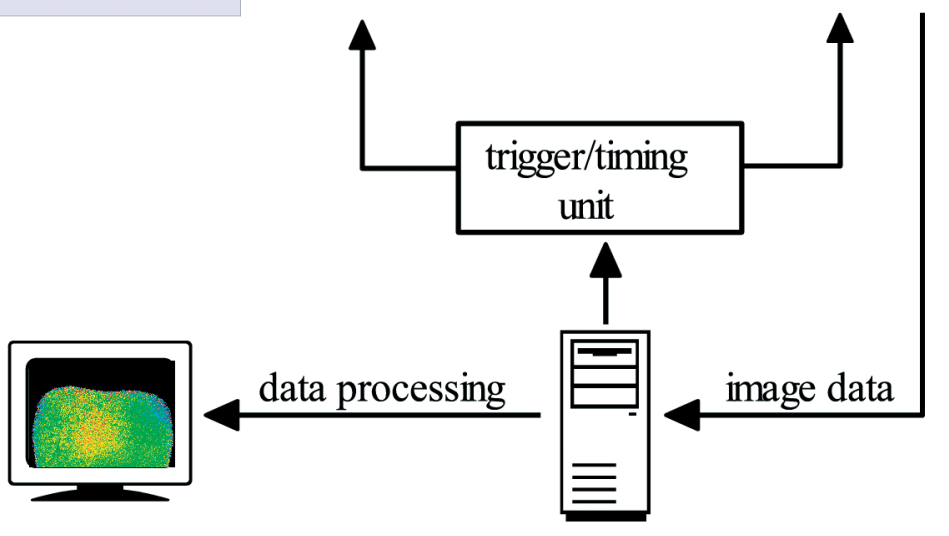

B

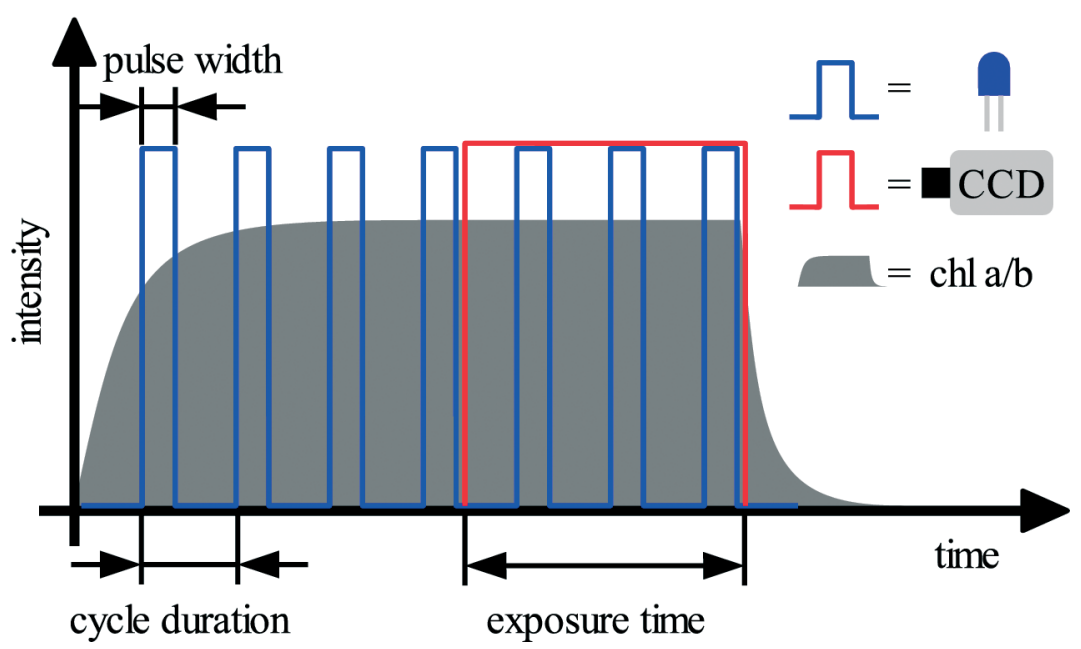

Fig. 1. A. Schematic drawing of the imaging system for mapping variable Chl $a$ fluorescence. B. Timing scheme used for variable fluorescence imaging showing the various user-defined settings for LED pulse-width, cycle duration, and exposure time of the CCD camera. For a given pulse-width and a fixed total time length of the pulse series (maximally $450 \mathrm{~ms}$ ), the intensity of excitation light over the total time of the pulse series can be varied by adjusting the cycle duration time from longer (= fewer cycles = low intensity) to shorter duration (= more cycles $=$ high intensity). Depending on the intensity of the induced fluorescence, the electronic shutter of the CCD camera was opened for shorter or longer exposure times (up to the maximal exposure time of $450 \mathrm{~ms}$ ). 
mercially available (see e.g. Schreiber et al. 2003 and www.walz.com), and first applications in aquatic biology are underway (Hill et al. 2004, Ralph et al. in press).

In this technical communication we present a chlorophyll fluorescence imaging system based on the use of modulated blue light emitting diode (LED) excitation light in connection with a sensitive modulated charge-coupled device (CCD) camera. We show applications of the system for mapping the quantum yield of photosystem II and the derived relative photosynthetic electron transport rate in different types of aquatic photosynthetic microorganisms. Supplementary material and animations of the dynamic behaviour of Chl $a$ fluorescence in various systems is available at http://www. mbl.ku.dk/mkuhl/imaging.

\section{RESULTS AND DISCUSSION}

$$
\begin{gathered}
\text { Description of imaging system and } \\
\text { measuring protocol }
\end{gathered}
$$

The imaging system for monitoring variable fluorescence basically consists of a sensitive gate-able CCD camera (SensiMod VGA, PCO Computer Optics, Germany), a ring of blue LEDs (470 nm, Agilent, USA) as an excitation light source, a custom made timing device that controls the triggering of the camera and light source, and a PC for data acquisition (Figure 1A). The basic components of the system are identical with a previously described modular luminescence-lifetime imaging system for mapping oxygen concentration (Holst et al. 1998, Holst \& Grunwald 2001).

The CCD chip of the camera is cooled by a Peltier element and has a resolution of 12 bit gray scale with $640 \times 480$ pixels. The spatial resolution depends on the camera objective used. Our measurements in corals and ascidian tissue were done at a spatial resolution of $\sim 25-100 \mu \mathrm{m}$ per pixel. An adaptation of the system to a microscope and a dissection microscope is underway in order to realize chlorophyll fluorescence analysis at the level of single cells or chloroplasts.

A trigger input allows the control of an electronic shutter in the camera. The image acquisition can thus be modulated from an external trigger and timing device (see more details in Holst et al. 1998). The camera was equipped with a red long-pass filter (RG645, Schott, Germany) that separated the red fluorescence light from the blue excitation light. Actinic light, measuring light, and the saturation pulse for the variable fluorescence measurements were all generated by the same ring light of 24 ultra-bright blue LEDs with a peak emission at $470 \mathrm{~nm}$.

A custom-made timing device controlled the timing between camera and light source. It was programmed over a serial interface to generate pulses of a defined width, cycle duration, and length (Fig. 1B). Between the different schemes the pulse width was kept constant and the cycle duration was varied so that almost any light intensity between 0 and $~ 1000 \mu \mathrm{mol}$ photons $\mathrm{m}^{-2} \mathrm{~s}^{-1}$ could be realized. For the presented results we used a pulse width of $5 \mu$ s. The cycle duration was $1 \mathrm{~ms}$ for measuring light, 8 to 250 $\mu$ s for actinic light, and $5 \mu$ s for the saturation pulse. The length of a pulse series was always $450 \mathrm{~ms}$, i.e. the maximal exposure time of the camera. Depending on the intensity of the fluorescence signal, the electronic shutter of the camera was opened for a shorter period of time. The camera exposure time was e.g. maximally $30 \mathrm{~ms}$ during a saturation pulse.

The measuring light intensity was selected at a non-actinic level where no induction behavior of the fluorescence yield was observed over time, i.e. no dynamic rise and decline of fluorescence yield was observed after onset of the measuring light. This was checked by observing fluorescence yield pictures over time after switching on the measuring light. A measurement cycle consisted of three steps. First the actinic light intensity was selected and the sample was illuminated while multiple images with measuring light were taken to observe how the fluorescence yield reached a quasi steady state (F-image). At steady state, an image of apparent maximal fluorescence $\left(\mathrm{F}_{\mathrm{m}}\right.$ '-image) was taken during a saturating light pulse. Using the same measuring scheme in darkness, we could obtain pictures of the minimal fluorescent yield of dark-adapted samples $\left(\mathrm{F}_{0}\right)$, and of the maximal fluorescence yield $\left(\mathrm{F}_{\mathrm{m}}\right)$.

All acquired images were filtered for noise by setting pixel values in non-fluorescent parts of the pictures to zero (Fig. 2). Pictures of the effective quantum yield of PSII photochemical energy conversion $\left(\Phi_{\mathrm{P}}\right.$-image $)$ and of the relative rate of PSII related electron transport, rETR, were then calculated pixel-wise as (Genty et al. 1989, Kühl et al. 2001):

$$
\begin{aligned}
& \Phi_{\mathrm{P}}=\left(\mathrm{F}_{\mathrm{m}}{ }^{\prime}-\mathrm{F}\right) / \mathrm{F}_{\mathrm{m}}, \\
& \operatorname{rETR}=\Phi_{\mathrm{P}} \mathrm{E}_{0}(\mathrm{PAR})
\end{aligned}
$$




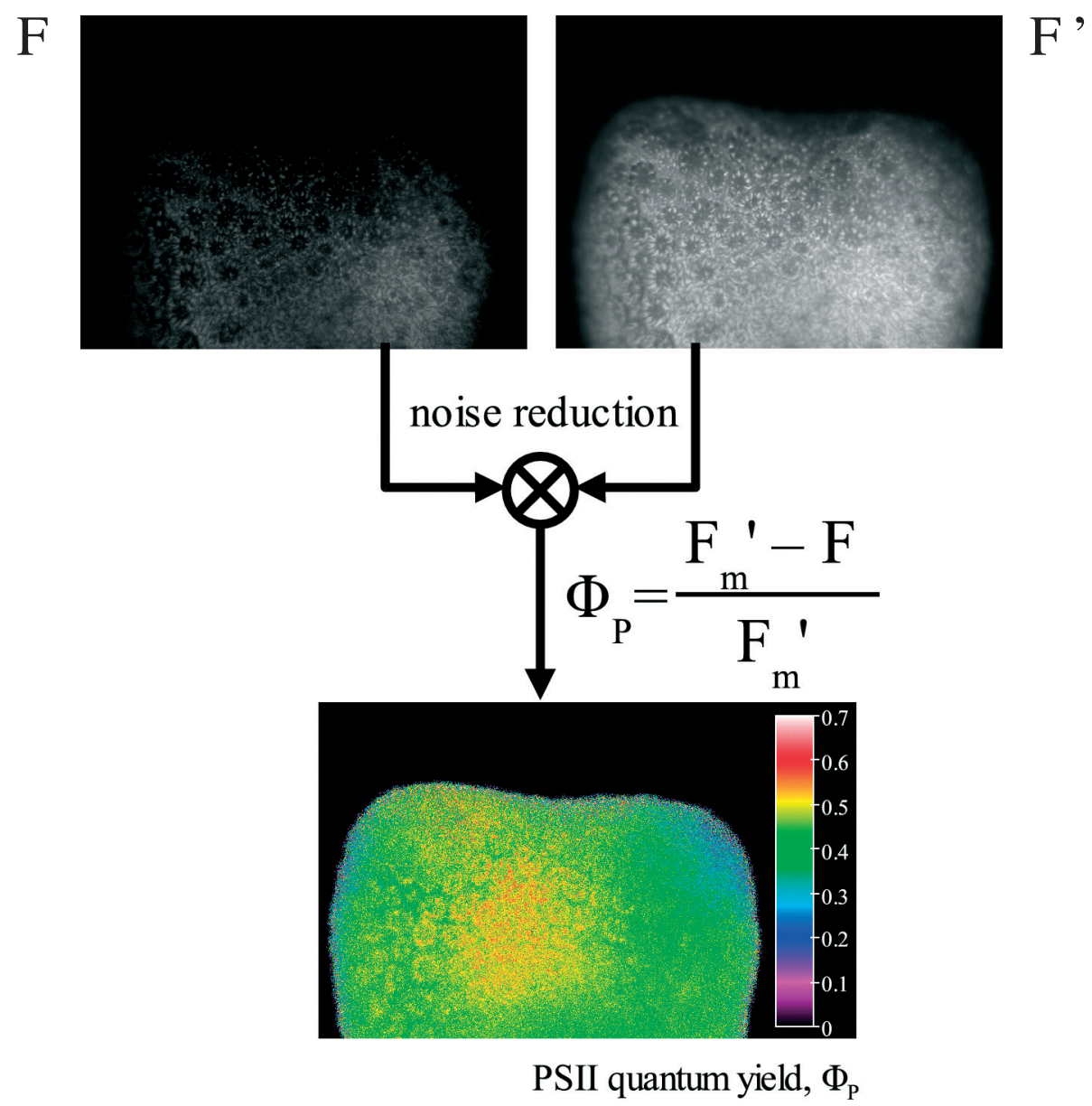

Fig. 2. An example of dark corrected pictures of fluorescence yield, F, the apparent maximal fluorescence yield, $\mathrm{F}_{\mathrm{m}}$ ', and the derived quantum yield of PSII activity of the the tip of a massive coral (Porites sp.). The color bar indicates the quantum yield.

where $\mathrm{E}_{0}(\mathrm{PAR})$ is the scalar irradiance integrated over 400-700 $\mathrm{nm}$.

The variable fluorescence imaging system was applied for studies of three different photosynthetic communities found on the reef flat off Heron Island, Great Barrier Reef, Australia. Our aim with these measurements was to show the potential of the new system rather than presenting detailed studies of photosynthesis regulation.

\section{Coral photosynthesis}

We first investigated a massive coral (Porites cylindrica) harboring dinoflagellate symbionts (zooxanthellae) in its tissue (Fig. 3). The colony tip (as seen from the side) showed a high PSII quantum yield of 0.50-0.65 when dark-adapted, indicating that the coral was not stressed by the experimental conditions and previous mechanical manipulations. At increasing irradiance the pictures of quantum yield showed an overall decrease all over the coral with a tendency for tissue areas more remote from the colony tip to show a larger decrease in yield, down to $\sim 0.3$, than tissue closer to the coral tip, which showed a PSII quantum yield of $\sim 0.4$ at the highest applied irradiance. At the level of single polyps, however, a strong heterogeneity in effective PSII quantum yield was seen between the polyp tissue and the surrounding coenosarc tissue (see inset in Fig. 3). Generally, coenosarc tissue showed a higher quantum yield than the polyp tissue at increasing irradiance, indicating acclimation of sym- 


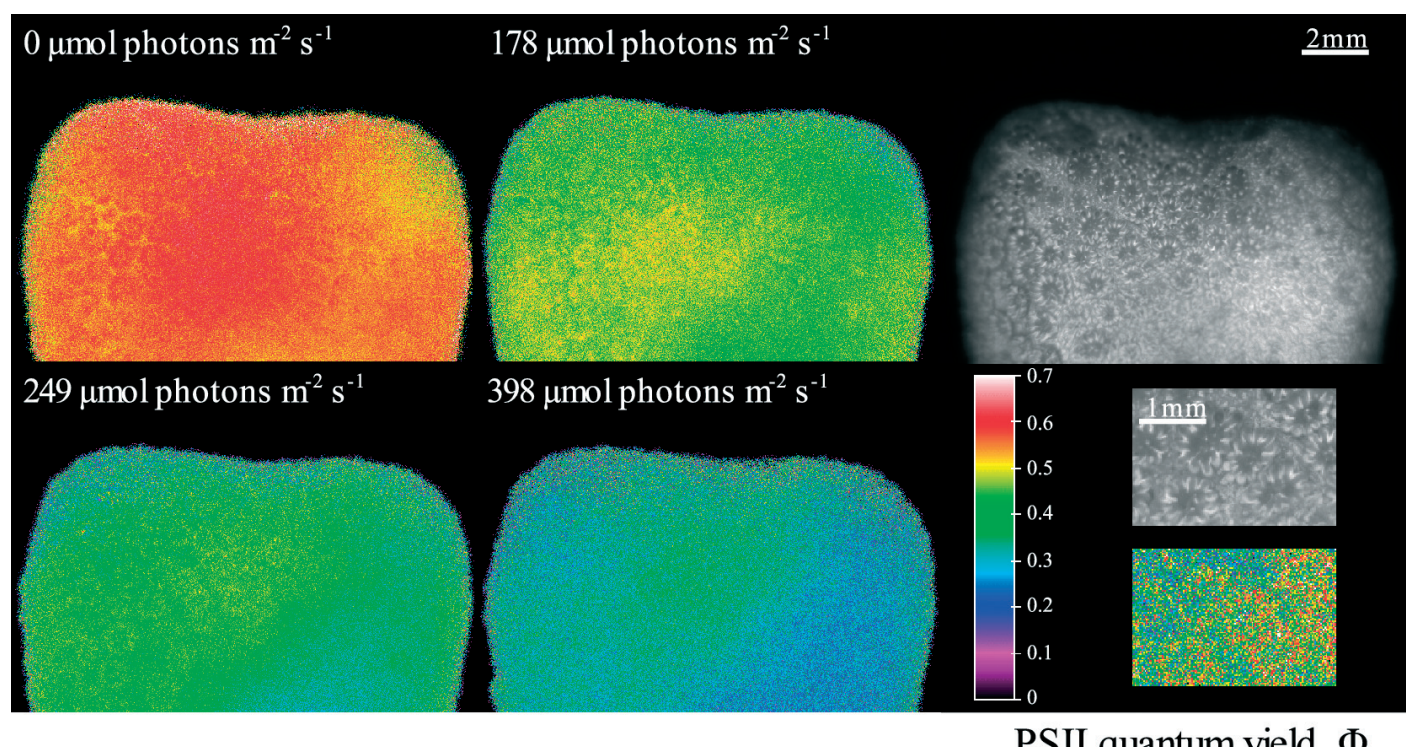

Fig. 3. Images of chlorophyll fluorescence (b/w pictures) and PSII quantum yield distribution (color-coded pictures) as a function of incident irradiance over a massive coral (Porites cylindrica). The inset shows close-up pictures from the same ares showing differences in the distribution of chlorophyll and PSII quantum yield at the level of a single polyp. The color bar shows the PSII quantum yield.

bionts in the coenosarc to higher irradiance.

Microsensor studies of corals (Favia sp.) have previously shown a pronounced heterogeneity in the distribution of photosynthesis (Kühl et al. 1995, DeBeer et al. 2000) with highest activities in the coenosarc and the mouth disk. Using a microfiber PAM-fluorometer with a spatial resolution of $\sim 200 \mu \mathrm{m}$, Ralph et al. (2002) showed (for Porites cylindrica and 5 other coral species) that symbiont photosynthesis in the coenosarc was generally less prone to downregulation at high irradiance than the polyp tissue, indicating differential acclimation to irradiance or the presence of differently adapted symbiont populations in different tissue compartments of corals.

Variable fluorescence imaging now allows for very detailed non-invasive studies of chlorophyll distribution in coral tissues simultaneous with measurements of the acclimation of symbiont photosynthesis in various regions of a coral colony. This approach has a clear advantage over previous non-modulated spectral imaging systems used to map the microdistribution of chlorophyll in corals (e.g. SimonBlecher et al. 1996). A detailed study of heterogeneity in photosynthetic activity of corals in relation to photoinhibition and temperature- induced bleaching was performed with a commercial imaging system and is presented elsewhere (Hill et al. 2004; Ralph et al. in press).

\section{Prochloron photosynthesis}

The colonial didemnid ascidian Diplosoma virens harbors a dense population of the still uncultured Chl $b$-containing cyanobacterium Prochloron sp. within cavities in its upper test (see Kühl and Larkum 2001 for a recent review). Water is drawn into the colony via numerous branchial apertures and then filtered through the branchial sac of the zooids before entering inter-connected cloacal cavities. These are lined by a dense Prochloron biofilm. From outside the colony, the Prochloron cells appeared as a dense green layer within the test (Fig. 4A). The chlorophyll fluorescence mapped from above or from the side showed a detailed picture of the Prochloron forming dense patches outlining the zooid morphology and the cloacal cavities (Fig. 4B).

Measured from above, the maximum PSII quantum yield was up to 0.83 , but values varied from $\sim 0.5-0.8$ across the didemnid colony especially around the edge of the colony. Both measuring light and the saturation pulse need 

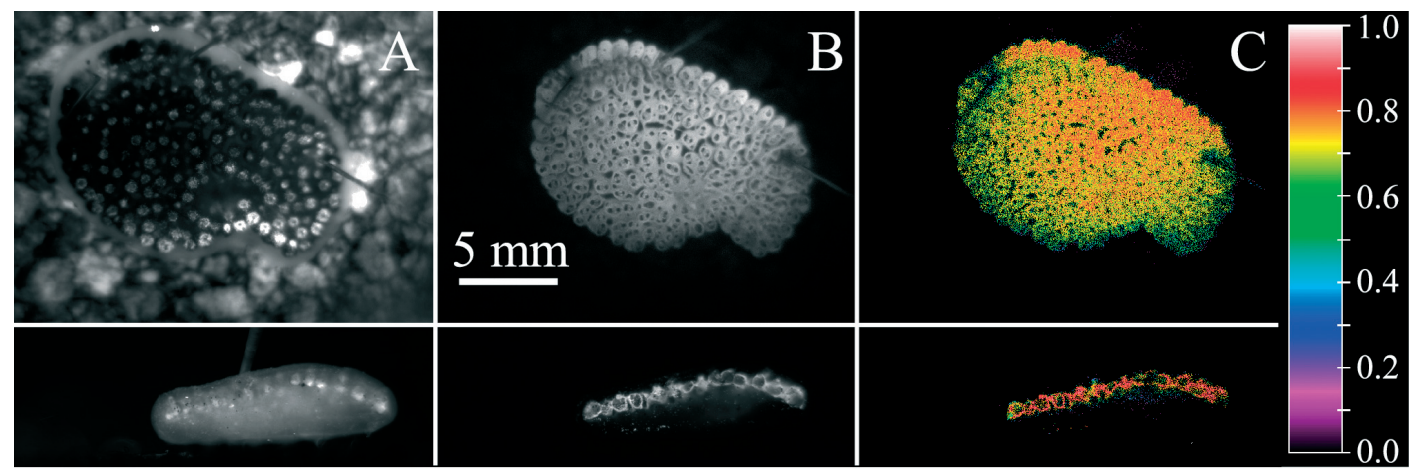

PSII quantum yield, $\Phi_{\mathrm{P}}$

Fig. 4. A colonial ascidian (Diplosoma virens) harboring a dense population of the Chl b-containing cyanobacterium Prochloron sp. in its upper test. A. Monochrome picture showing an intact colony at the top and a cut colony seen from the side. B. Chlorophyll fluorescence images of the same specimen. C. Images of maximum PSII quantum yield distribution in the same specimen. The color code denotes the PSII quantum yield.

to penetrate through the $200-500 \mu \mathrm{m}$ thick upper test before reaching the Prochloron. The test material contains UV screening pigments with an absorption spectrum that extends into the blue region of visible light (Dionisio-Sese et al. 1997). The uneven distribution of maximal PSII quantum yield may thus be due to variations in the surface topography of the upper test material causing attenuation of the saturation pulse to non-saturating levels. When measuring from the side on a tissue slice a more homogeneous PSII quantum yield of $\sim 0.7-0.8$ was observed in the Prochloron layer (Fig. 4C lower panel), which was directly exposed to the incident light without attenuation in the test material.
The high maximum PSII quantum yield of Prochloron is remarkable among cyanobacteria and similar high values have previously been found only in terrestrial plant leaves (Schreiber et al. 1997). Prochlorophytes are the only photosynthetic prokaryotes containing $\mathrm{Chl} b$, and their photosynthetic apparatus differ from other cyanobacteria (see references in Kühl \& Larkum 2001). Unfortunately, Prochloron has so far resisted all cultivation attempts and most studies have involved isolated cells that do not survive long when removed from the host tissue. Our knowledge about Prochloron ecophysiology in its natural habitat is therefore still limited. With the new imaging system we could for the first time visualize details of the distribution
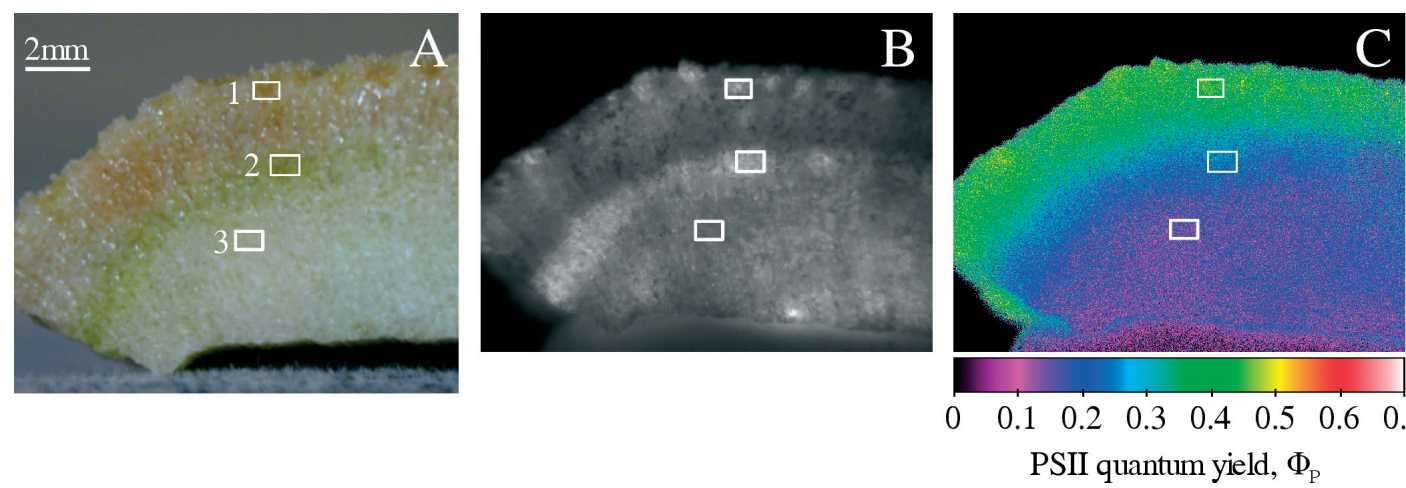

Fig. 5. A massive coral (Cyphastrea sp.) harboring endolithic microalgae and bacteria in its skeleton. A. Color photograph showing the brown surface zone with coral polyp tissue, a green band of endolithic algae and the white skeleton below. B. Image of chlorophyll fluorescence distribution in the sample. C. Color-coded image of PSII quantum yield distribution in the sample measured at high irradiance $\left(240 \mu \mathrm{mol}\right.$ photons $\left.\mathrm{m}^{-2} \mathrm{~s}^{-1}\right)$. Small highlighted squares indicate areas with polyp tissue (1), endolithic algae (2), and coral skeleton (3) referred to in Fig. 6. 


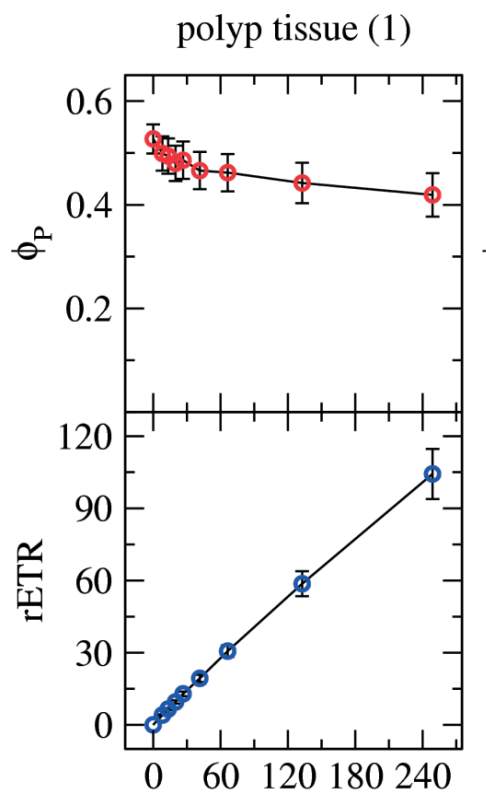

endolithic algae band (2)

coral skeleton (3)
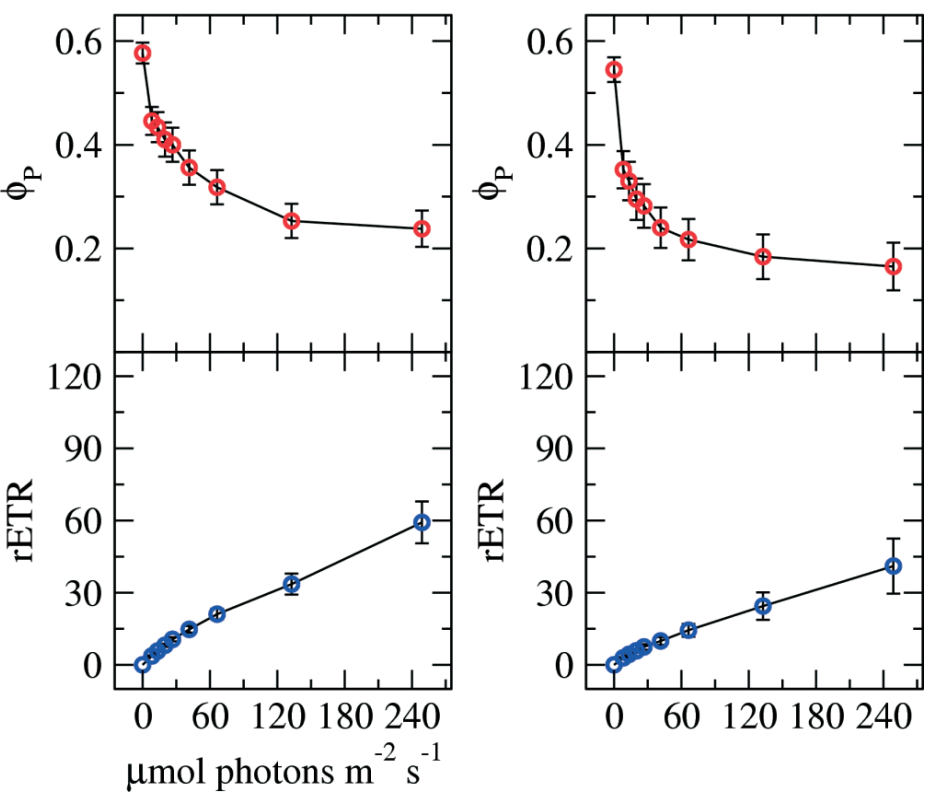

Fig. 6. Quantum yield of PSII and the relative electron transport rate as a function of increasing irradiance within the three zones outlined in Fig. 5. Symbols and error bars denote the mean \pm standard deviation.

and photosynthetic activity of Prochloron in hospite within its ascidian host. Earlier studies have relied on a few point measurements with microsensors (Kühl \& Larkum 2001) or fiberoptic variable fluorescence meters (Schreiber et al. 1997). Our results show that it is possible to manipulate the intact symbiosis without significant decrease in photosynthetic performance of Prochloron and this will enable future studies of how the ascidian-Prochloron symbiosis is responding to environmental changes or e.g. how wounding or other types of stress on the ascidian host are influencing the symbiosis.

\section{Endolithic photosynthesis in coral skeleton}

Endolithic microalgae can form dense bands in the skeleton of many corals. Often the endolithic community is dominated by the green alga Oestreobium quekettii belonging to Phyllosiphonidae (Le Campion-Alsumard et al. 1995), but also other phototrophic microorganisms like cyanobacteria and even bacteriochlorophyll-containing photosynthetic bacteria can be found in the skeleton (Ralph et al. in prep.).
The activity and microenvironment of endoliths under their natural conditions inside the coral skeleton are largely undescribed (but see e.g. Shashar \& Stambler 1992, Schlichter et al. 1997).

By applying the new imaging system on a vertically cut coral (Cyphastrea sp.) we could measure the depth distribution of chlorophyll and show the presence of distinct layers in the skeleton with different photosynthetic performance (Fig. 5). The upper $\sim 2 \mathrm{~mm}$ thick brownish part of the coral was dominated by coral polyp tissue with zooxanthellae, while a $1-2 \mathrm{~mm}$ thick green band of endolithic algae was present 3-4 mm below the coral surface (Fig. 5A). Deeper layers in the coral skeleton appeared white, but pictures of chlorophyll fluorescence revealed the presence of active chlorophyll throughout the skeleton (Fig. 5B). Imaging of the PSII quantum yield at $240 \mu \mathrm{mol}$ photons $\mathrm{m}^{-}$ $2 \mathrm{~s}^{-1}$ showed a distinct zonation through the vertical section with the highest yield of $\sim 0.4-0.5$ in the coral tissue layer, a somewhat lower yield of $\sim 0.3$ in the green endolithic layer, and the lowest yield of $\sim 0.1-0.2$ in the deeper skeleton layers (Fig. 5C). 
We also recorded pictures of a complete light curve of rETR vs. irradiance starting with the dark-adapted sample (Fig. 6). The maximum PSII quantum yields averaged over $\sim 0.5-1 \mathrm{~mm}^{2}$ of the polyp tissue, the endolithic band and the coral skeleton below were $0.53 \pm 0.02$ (mean \pm standard deviation), $0.57 \pm 0.02$, and $0.55 \pm$ 0.02 , respectively. These high yields are typical for healthy algae and indicate that the sample was apparently not stressed by the experimental conditions or mechanical manipulations prior to the measurements. While all zones thus showed a high maximum PSII quantum yield, a distinct difference in photosynthetic performance of the various layers in the skeleton was observed at increasing irradiance (Fig. 6 ). The top layer with coral tissue exhibited a relatively small decrease in PSII quantum yield of $\sim 0.1$ over the experimental range of irradiances, while the quantum yield in both the endolithic band and the coral sketon decreased $\sim 0.3-0.4$ units from the lowest to the highest applied irradiance (Fig. 6, upper panels) showing that these layers were acclimated to a low irradiance regime inside the skeleton.

The rETR vs. irradiance curve was steepest and increased almost linearly with irradiance in the top layer with coral tissue. In the endolithic band and in the skeleton, the photosynthetic efficiency was lower, i.e. the rETR vs. irradance curves were less steep (Fig. 6, lower panel) and started to curve towards saturation already at low irradiance. Despite a significant decrease in quantum yield already at $<30 \mu \mathrm{mol}$ photons $\mathrm{m}^{-2} \mathrm{~s}^{-1}$, we did not observe saturation of the rETR with the applied irradiances in the endolith layers. Extrapolation of the measured curves, indicate that the $\mathrm{ETR}_{\max }$ at saturation would be highest in the polyp tissue with zooxanthellae followed by the endolithic layer and the phototrophs in the coral skeleton. However, it is also possible that layers more distant from the skeleton surface contributed to the fluorescence signals at higher actinic irradiances in the zones containing endoliths, i.e. that saturation or inhibition of endoliths at the surface was partly compensated by increased activity of endoliths deeper in the skeleton. This is supported by recent measurements on endoliths in three different corals with fiberoptic PAM fluorometers and an oxygen imaging system showing saturation of photosynthesis at irradiances $<50 \mu \mathrm{mol}$ photons $\mathrm{m}^{-2} \mathrm{~s}^{-1}$ (Ralph et al. in prep.). Variations in the operational volume sampled with the fluorescence imaging technique at different light levels will be highly dependent on the optical properties of the sample and if significant, such variations would smear out distinct heterogeneities in the sample and decrease the spatial resolution.

\section{SUMMARY}

The presented chlorophyll fluorescence imaging system can map the two-dimensional distribution of photosynthetic activity in aquatic systems at high spatial resolution. Our measurements in corals and ascidian tissue were done at a spatial resolution of $\sim 25-100 \mu \mathrm{m}$ per pixel and this enabled us to map the heterogeneous distribution of photosynthetic activity in coral and ascidian tissues and inside coral skeleton. However, the resolution of the system is mainly determined by the optical configuration of the camera and the LED light sources. An adaptation of the system to a microscope and a dissection microscope is thus underway to realize chlorophyll fluorescence analysis at the single cell or chloroplast level. Here we have only presented data showing pictures of PSII quantum yield and derived relative electron transport rates. Also other types of quenching analysis (see details in Schreiber et al. 1995) like e.g. indices for non-photochemical quenching can be carried out on the image data recorded by the system. A particularly attractive feature of the presented system in comparison to other chlorophyll fluorescence systems is the possibility to use exactly the same system configuration for two-dimensional oxygen measurements with transparent optodes (Holst et al. 1998, Holst \& Grunwald 2001) in combination with variable fluorescence imaging; i.e. by a simple switch of the operating software and the filter in front of the CCD camera. Another future development will thus be to implement variable fluorescence measurements on a recently developed in situ instrument for autonomous mapping of oxygen distributions in the sea floor (Glud et al. 2001). Here we have demonstrated the potential of the new imaging system in coral reef studies. However, the possibility to simultaneously image the distribution of chlorophyll and photosynthetic activity is of general advantage in studies of most surface-associated photosynthetic communities such as e.g. stratified microbial mats or motile populations of microalgae in tidal sediments. 


\section{MATERIALS AND METHODS}

\section{Sampling sites and treatment}

All measurements were conducted during a field trip to Heron Island Research Station in January 2001. The measurements were performed in the laboratory at $\sim 28^{\circ} \mathrm{C}$ room temperature, which was approximately the same as the ambient water temperature on the Heron Island reef flat. Corals (Porites cylindrica and $\mathrm{Cy}$ phastrea sp.) and ascidians were collected from the Heron Island lagoon $\left(152^{\circ} 6^{\prime} \mathrm{E}, 20^{\circ} 29^{\prime} \mathrm{S}\right)$ and kept outdoors in semi-shaded aquaria that were flushed continuously with fresh seawater. The Cyphastrea samples were used for studying endolithic algae in the coral skeleton and were cut in half with a diamond-tipped saw under shaded conditions and under a continuous flow of seawater. Once cut, the samples were put on a black plastic surface to prevent light damage to the endolithic algae. The laboratory experiments were done with the samples positioned in a small flow chamber, which was continuously flushed with fresh aerated seawater (see also Fig. 1). Light levels in the measuring set-up were determined with a small quantum scalar irradiance probe connected to a PAMCONTROL meter (both from Walz GmbH, Germany). The response of the scalar irradiance probe was calibrated against the reading of another scalar irradiance meter (QSL-101, Biospherical Instruments, USA).

\section{Variable fluorescence measurements}

Here we give a brief introduction to key variable fluorescence parameters used to quantify PSII related electron transport via the so-called saturation pulse method. We use the nomenclature recommended by Van Kooten \& Snel (1990). A detailed description of variable fluorescence techniques is not the scope of the present paper and can be found elsewhere (e.g. Schreiber et al. 1995, Falkowski \& Raven 1997).

When a photosynthetic sample is illuminated with modulated weak excitation light pulses, it is possible to monitor the chlorophyll fluorescence yield without inducing an actinic effect on the photosynthetic apparatus. With a special pulse-amplitude modulation technique such measurements can be made independent of ambient or background light, which can be orders of magnitude higher (Schreiber et al. 1986).

Chlorophyll fluorescence at environmental temperatures is mainly originating from PSII and associated antenna pigments. In the darkadapted state PSII is completely open and the sample exhibits a minimal fluorescence yield, $\mathrm{F}_{0}$, which originates mainly from the antenna pigments. $\mathrm{F}_{0}$ has been shown to be a good proxy for chlorophyll biomass (e.g. Serodio et al. 1997). When actinic light is present PSII becomes partly closed and the fluorescence yield increases and exhibits a transient induction behavior (known as the Kautsky curve) before approaching a steady state level, F, which is higher than $\mathrm{F}_{0}$. Complete closure of PSII, can be induced by a brief (0.4 - $0.8 \mathrm{~s})$ saturation pulse of high irradiance leading to a maximal fluorescence yield, $\mathrm{F}_{\mathrm{m}}$. The maximal fluorescence yield measured in the dark-adapted state is denoted $\mathrm{F}_{\mathrm{m}}$. In the presence of significant non-photochemical quenching of fluorescence e.g. due to heat dissipation $\mathrm{F}_{\mathrm{m}}$, is $<\mathrm{F}_{\mathrm{m}}$.

It has been shown (Genty et al. 1989) that the effective quantum yield of charge separation in PSII, $\Phi_{\mathrm{p}}$, can be estimated from the fluorescence yield measurements mentioned above as $\Phi_{\mathrm{p}}=\left(\mathrm{F}_{\mathrm{m}} \mathrm{-F}\right) / \mathrm{F}_{\mathrm{m}}$. Note that this measurement does not necessarily require a previous $\mathrm{F}_{0}$ determination. The maximal PSII quantum yield is measured with fully dark-adapted samples as $\left(\mathrm{F}_{\mathrm{m}}-\mathrm{F}_{0}\right) / \mathrm{F}_{0}$, and this parameter is often used as an index of healthiness in studies where phototrophs are exposed to various stress factors such as UV radiation or temperature. Maximum PSII quantum yields of diatoms, dinoflagellates and cyanobacteria are typically within the range of 0.50-0.65.

The photosynthetic electron transport rate (ETR) from PSII under a given irradiance, $\mathrm{E}_{0}(\mathrm{PAR})$, can be derived from the quantum yield as $\mathrm{ETR}=\Phi_{\mathrm{p}} \sigma_{\mathrm{a}} \mathrm{E}_{0}(\mathrm{PAR})$, where $\sigma_{\mathrm{a}}$ is the absorption cross-section of PSII. While $\sigma_{\mathrm{a}}$ can be determined by other techniques (e.g. Kolber \& Falkowski 1993), in many applications $\sigma_{\mathrm{a}}$ is unknown. Consequently, relative rates of PSII-related electron transport can be calculated as $\mathrm{rETR}=\Phi_{\mathrm{p}} \mathrm{E}_{0}(\mathrm{PAR})$. We have used this approach in the present study.

Measurements of $\Phi p$ after incubation under increasing levels of actinic light allows the construction of a rETR vs. irradiance curve that can be analyzed like photosynthesis vs. irradiance curves (see e.g. Kühl et al. 2001) to obtain parameters like the initial slope, the irradiance at the onset of saturation and $\mathrm{rETR}_{\max }$, which characterize the photosynthetic performance of the investigated sample. Using short (10-20 s) incubation periods at each level of actinic 
irradiance so-called rapid light-curves (Schreiber et al. 1997) can be measured, which provide a snapshot of the acclimation of photosynthesis to ambient light regime just prior to measurement. When longer incubation periods (minutes to hours) are used at each actinic light level, the sample is allowed to acclimate to the applied irradiance e.g. by changes in $\sigma_{\mathrm{a}}$, by regulation of photosynthesis via the xanthophyll cycle or other types of excess energy dissipation. In the present study we measured the latter type of rETR vs. irradiance curves.

\section{ACKNOWLEDGEMENTS}

This study was funded by the Danish Natural Science Research Council (MK), the Max-Planck Society (Germany; BG), and the EU project COSA (EVK3-CT20020076). We appreciate the help of Gerhard Holst and Rolf Gademann with solving technical problems and for discussions and valuable suggestions for system improvements. Peter Ralph, Tony Larkum and Ove HoeghGuldberg are thanked for providing the specimens used in this study and for discussions and encouragements during the first design and test phase of the imaging system at the Heron Island Research Station (HIRS) in January 2002. Ulrich Schreiber is thanked for his continuous support and many fruitful discussions about fluorescence analysis of photosynthesis. The staff of HIRS is thanked for excellent technical assistance. The Marine Science Center of the University of Queensland, Brisbane (Australia), generously covered bench fees for our stay on Heron Island.

\section{REFERENCES}

Berman-Frank, I., P. Lundgren, Y.-B. Chen, H. Küpper, Z. Kolber, B. Bergman \& P. Falkowski. 2001. Segregation of nitrogen fixation and oxygenic photosynthesis in the marine cyanobacterium Trichodesmium. Science 294: 1534-1537.

De Beer, D., M. Kühl, N. Stambler \& L. Vaki. 2000. A microsensor study of light enhanced $\mathrm{Ca}^{2+}$ uptake and photosynthesis in the reef-building hermatypic coral Favia sp. Marine Ecology Progress Series 194: 75-85.

Dionisio-Sese, M.L., M. Ishikura, T. Maruyama \& S. Miyachi. 1997. UV-absorbing substances in the tunic of a colonial ascidian protects its symbiont, Prochloron sp., from damage by UV-B radiation. Marine Biology 128: 455-461.

Falkowski, P.G. \& J.A. Raven. 1997. Aquatic photosynthesis. Blackwell, Malden.

Fenchel, T. \& R.N. Glud. 2000. Benthic primary production and $\mathrm{O}_{2}-\mathrm{CO}_{2}$ dynamics in a shallow-water sediment: spatial and temporal heterogeneity. Ophelia 53: 159-171.

Genty, B., J.M. Briantais \& N. Baker. 1989. The relationship between the quantum yield of photosynthetic electron transport and quenching of Chl fluorescence. Biochimica et Biophysica Acta 990: 87-92.

Glud, R.N., M. Kühl, O. Kohls \& N. B. Ramsing. 1999. Heterogeneity of oxygen production and consumption in a photosynthetic microbial mat as studied by planar optodes. Journal of Phycology 35: 270-279.

Gorbunov, M.Y., P.G. Falkowski \& Z. Kolber. 2000. Measurements of photosynthetic parameters in benthic organisms in situ using a SCUBA-based fast repetition rate fluorometer. Limnology and Oceanography 45: 242-245.

Govindjee. 1995. Sixty-three years since Kautsky: Chlorophyll a fluorescence. Australian Journal of Plant Physiology 22: 131-160.

Hill, R., U. Schreiber, R. Gademann, A. W. D. Larkum, M. Kühl \& P. Ralph. 2004. Spatial heterogeneity of photosynthesis and the effect of temperature-induced bleaching conditions in three species of corals. Marine Biology 144: 633-640.

Holub, O., M.J. Seufferfeld, C. Gohlke, Govindjee \& R. M. Clegg. 2000. Fluorescence lifetime imaging (FLI) in real-time - a new technique in photosynthesis research. Photosynthetica 38: 581-599.

Holst, G., O. Kohls, I. Klimant, B. König, M. Kühl \& T. Richter. 1998. A modular luminescence lifetime imaging system for mapping oxygen distribution in biological samples. Sensors and Actuators B 51: 163-170.

Holst, G. \& B. Grunwald. 2001. Luminescence lifetime imaging with transparent oxygen optodes. Sensors and Actuators B 74: 78-90.

Kolber, Z. \& P.G. Falkowski. 1993. Use of fluorescence to estimate phytoplankton photosynthesis in situ. Limnology and Oceanography 38: 1646-1665.

Kühl, M., Y. Cohen, T. Dalsgaard, B.B. Jørgensen \& N.P. Revsbech. 1995. Microenvironment and photosynthesis of zooxanthelllae in scleractinian corals studied with microsensors for $\mathrm{O}_{2}, \mathrm{pH}$ and light. Marine Ecology Progress Series 117: 159-172.

Kühl, M. \& T. Fenchel. 2000. Bio-optical characteristics and the vertical distribution of photosynthetic pigments and photosynthesis in an artificial cyanobacterial mat. Microbial Ecology 40: 94-103.

Kühl, M., R.N. Glud, J. Borum, R. Roberts \& S. Rysggard. 2001. Photosynthetic performance of surfaceassociated algae below sea ice as measured with a pulse-amplitude - modulated (PAM) fluorometer and $\mathrm{O}_{2}$ microsensors. Marine Ecology Progress Series 223: 114.

Kühl, M. \& A.W.D. Larkum. 2001 The microenvironment and photosynthetic performance of Prochloron sp. in symbiosis with didemnid ascidians. In: Seckbach, J. (ed.), Cellular origin and life in extreme habitats Vol. 3: Symbioses, mechanisms and model systems. Kluwer Acad. Publ., Dordrecht, 273-290.

Le Campion-Alsumard, T., S. Golubic \& P. Hutchings. 1995. Microbial endoliths in skeletons of live and dead corals, Porites lobata (Moorea, French Polynesia). Marine Ecology Progress Series 117: 149-157.

Nedbal, L., J. Soukupova, D. Kaftan, J. Whitmarsh \& M. Tritlek. 2000. Kinetic imaging of chlorophyll fluorescence using modulated light. Photosynthesis Research 66: $3-12$.

Oxborough, K. \& N. R. Baker. 1997. An instrument capable of imaging chlorophyll $a$ fluorescence from intact leaves at very low irradiance and at cellular and subcellular levels of organization. Plant Cell E Environment 20: 1473-1483.

Oxborough, K., A.R.M. Hanlon, G.J.C Underwood \& N.R. Baker. 2000. In vivo estimation of the photosystem II photochemical efficiency of individual microphytobenthic cells using high-resolution imaging of 
chlorophyll a fluorescence. Limnology and Oceanography 45: 1420-1425.

Ralph, P.J., R. Gademann \& W.C. Dennison. 1997. In situ seagrass photosynthesis measured using a submersible pulse-amplitude modulated fluorometer. Marine Biology 132: 367-373.

Ralph, P.J., R. Gademann, A.W.D. Larkum \& Kühl, M. 2002. Spatial heterogeneity in fluorescence response of coral tissues. Marine Biology 141: 639-646.

Ralph, P.J., A.W.D. Larkum, M. Kühl \& G. Holst. Photobiology of coral endolithic algae (in preparation).

Ralph, P. J., U. Schreiber, R. Gademann, A. W. D. Larkum \& M Kühl. Coral photobiology studied with a new imaging PAM fluorometer. Journal of Phycology (in press).

Schlichter, D., H. Kampmann \& S. Conrady. 1997. Trophic potential and photoecology of endolithic algae living within coral skeletons. P.S.Z.N. Marine Ecology 18: 299-317.

Schreiber, U., U. Schliwa \& W. Bilger. 1986. Continuous recording of photochemical and non-photochemical chlorophyll fluorescence quenching with a new type of modulation fluorometer. Photosynthesis Research 10: 51-62.

Schreiber, U., W. Bilger \& C. Neubauer. 1995. Chlorophyll fluorescence as a non-intrusive indicator for rapid assessment of in vivo photosynthesis. In: Schulze, E.-D., M.M. Caldwell (eds.) Ecophysiology of photosynthesis. Springer, Berlin/Heidelberg, 49-70.

Schreiber, U., M. Kühl, I. Klimant \& H. Reising. 1996.
Measurement of chlorophyll fluorescence within leaves using a modified PAM fluorometer with a fiberoptic microprobe. Photosynthesis Research 47: 103-109.

Schreiber, U., R. Gademann, P.J. Ralph \& A.W.D. Larkum. 1997. Assessment of photosynthetic performance of Prochloron in Lissoclinum patella in hospite by chlorophyll fluorescence measurements. Plant Cell Physiology 38: 945-951.

Schreiber, U., H. Walz \& J. Kolbowski. 2003. Propagation of spatial variations of chlorophyll fluorescence parameters in dandelion leaves induced by laser spot heating. PAM News 2003 (01), http://www.pam-news. com/ar/03-01/PAM-News-03-01.html.

Serodio, J., J. Marques da Silva \& F. Catarino. 1997. Nondestructive tracing of migratory rhytms of intertidal benthic microalgae using in vivo chlorophyll a fluorescence. Journal of Phycology 33: 542-553.

Shashar, N. \& N. Stambler. 1992. Endolithic algae within corals - life in a protected environment. Journal of Experimental Marine Biology and Ecology 163: 277-286.

Siebke, K. \& E. Weiss. 1995. Imaging of chlorophyll $a$ fluorescence in leaves: topography of photosynthetic oscillations in leaves of Glechoma hederacea. Photosynthesis Research 45: 225-237.

Simon-Blecher, N., Y. Achituv \& Z. Malik. 1996. Effect of epibionts on the microdistribution of chlorophyll in corals and its detection by fluorescence spectral imaging. Marine Biology 126: 757-763.

Van Kooten, O. \& J.F.H. Snel. 1990. The use of chlorophyll fluorescence nomenclature in plant stress physiology. Photosynthesis Research 25: 147-150. 
